\title{
Discontinuous Crack Propagation
}

\section{D. JAfFE,* Junior Member, AIME, E. L. REED,* and H. C. MANN*}

It has been generally believed that fracture originates at a point and, if the stress is sufficient, propagates across the material from this point. Evidence to the contrary is given in Fig 1. This micrograph shows an area close to the fracture of a steel containing

\begin{tabular}{c|c|c|c|c|c}
\hline $\mathrm{C}$ & $\mathrm{Mn}$ & $\mathrm{Si}$ & $\mathrm{Cr}$ & $\mathrm{Mo}$ & $\mathrm{V}$ \\
\hline 0.28 & 0.74 & 0.20 & 1.00 & 0.49 & 0.12 \\
\hline
\end{tabular}

The material had been quenched from $1675^{\circ} \mathrm{F}$ and tempered at $1150^{\circ} \mathrm{F}$ as a round about 10 in. in diam, and had a static tensile strength of 132,000 psi and a static yield strength of 105,000 psi. The steel was broken in 3000 cycles of reversed bending at a nominal max. fiber stress of 110,000 psi at a speed of $10,000 \mathrm{rpm}$. It was in the form of a standard R.R. Moore specimen with $45^{\circ} \mathrm{V}$-notch, 0.015 in. radius and 0.220 in. diam at base of notch. The fractured edge in Fig 1 is part of the central portion of the specimen which broke during the final sudden fracture.

Attention is directed to the short cracks which appear as dark lines within the specimen. Similar cracks were found in another specimen of the material, broken in $1,798,000$ cycles at a nominal stress of 40,000 psi. The cracks were found in several areas close to the path of the final sudden fracture. This final fracture appeared microscopically to be wholly brittle and transcrystalline. Closer to the surface of the specimens, near the path of progressive fracture, which presumably advanced gradually during many cycles, there was microscopic evidence of some local deformation, but no microcracks. Neither were microcracks observed in areas distant from the main fracture path.

The following explanation is offered: In the sudden fracture of the specimen, a crack propagates along a crystallographic plane, with little or no plastic deformation of the adjacent material, until it reaches a grain boundary or a particle of carbide or inclusion which stops its advance. (The particle or boundary may be outside the plane of polish and not visible in the micrograph.) A stress concentration occurs about the end of the stopped crack. One or more new cracks are likely to start in the zone of this stress concentration. They may lie in the same grain as the first crack or in an adjacent

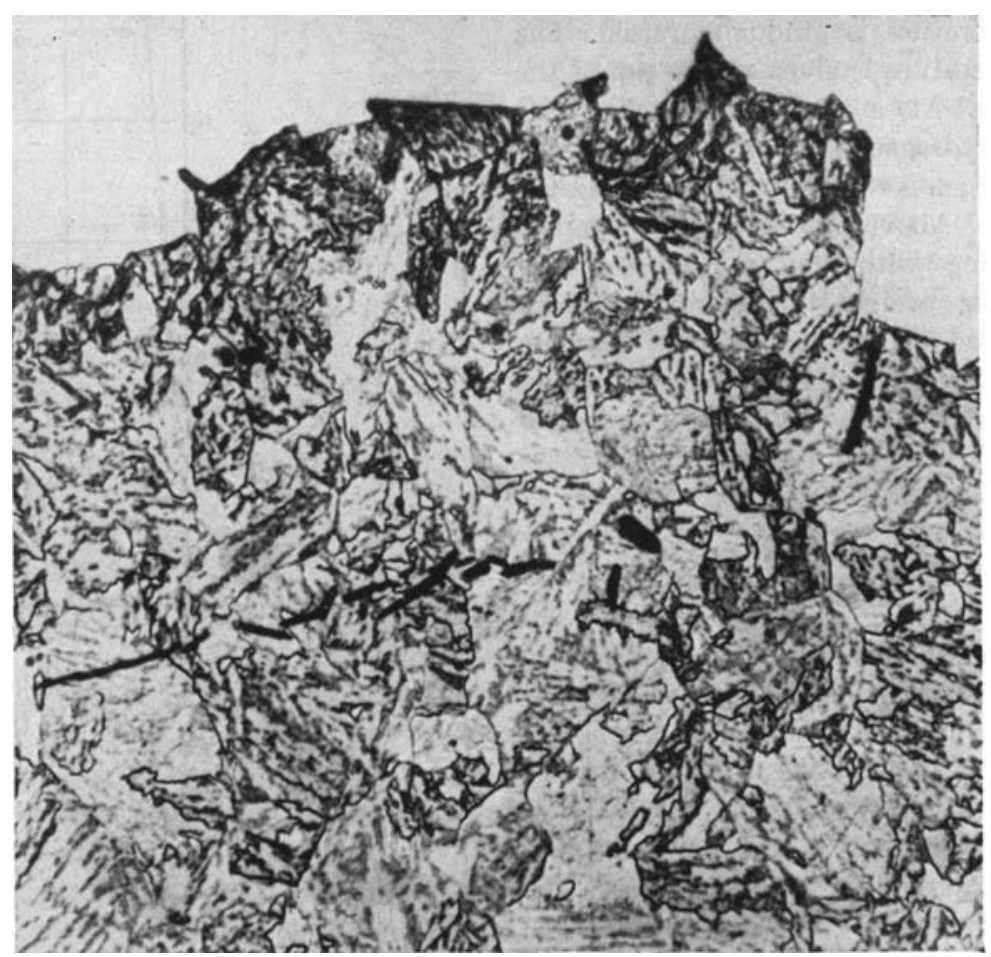

FIG 1-Microcracks near fracture of fatigue test specimen. $\times 500$. Vilella etch.

grain. New cracks may occasionally start in a nearby but not adjacent grain whose orientation with respect to the stress leads to more ready fracture than does that of the grain between. Once started, these cracks propagate along crystallographic planes in their grains and the process repeats. This leads to discontinuous, branching chains of microcracks.

As the process continues, microcracks probably tend to link up by fracture of intermediate material under the influence of increasing stress concentration. Occasionally, too, there may be a series of nearby grains of similar orientation so that there is a certain continuity of fracture across them. In either case the effective size of a crack is increased, resulting in greater stress concentration at its ends and a greater likelihood of further increase of size of the continuously-fractured region. When one continuous crack crosses the entire specimen, macroscopic fracture has occurred. The fractured edge of the specimen in Fig 1 represents a

Technical Note No. 16 E. This note has been published by permission of National Millitary Establishment. Manuscript received April 4, 1949.

* Watertown Arsenal Laboratory, Watertown, Mass. series of microcracks which became continuous across the entire specimen. The short, dark-appearing cracks in the figure did not become continuous over a large area. The row of microscopic stress concentrations at their ends may link up with those of the "main crack" outside the plane of polish.

The above explanation does not imply that microcracks develop at the same rate in all portions of the specimen. They will develop most rapidly where the macroscopic tensile stress and macroscopic stress concentration are greatest. Viewed on a scale large compared to the grains, the fracture would appear to progress continuously across the specimen.

Although Fig 1 shows a specimen broken in a fatigue test, it is believed that the microcracks discussed do not depend on the repetitive nature of the stressing used, since they are in the region where "sudden" fracture occurred, presumably in a single stress cycle. The whole process of microcrack propagation outlined above is thought to have occurred during this single cycle.

It is believed that discontinuous crack propagation may be universal in brittle transgranular fracture of crystalline solids. Further experiments are under way. 